\title{
Study of the velocity of upper canine retraction after alveolar corticotomy
}

\author{
A. Mezari' ${ }^{1}$ F. Si Ahmed ${ }^{2}$ \\ 1 Lecturer in DFO - Faculty of Medicine of Algiers - Department of Dental Medicine / Hospital \\ Practitioner at $\mathrm{CHU}$ Alger Center \\ 2 Professor of DFO - Faculty of Medicine of Algiers - Department of Dental Medicine
}

\section{SUMMARY}

\begin{abstract}
The purpose of this study was to evaluate the efficacy of alveolar corticotomy on orthodontic tooth movement when retracting upper canines compared with the conventionnal treatment. The sample consisted of 30 patients with a mean age of $21 \pm 2$ years requiring the therapeutic extraction of the maxillary first premolars, with subsequent retraction of the maxillary canines. The subjects were divided into two groups, one receiving orthodontic treatment assisted corticotomy (experimental group) and the other conventional treatment (control group). The velocity of the retraction of the upper canine was evaluated by measuring the distance between the canine and second premolar on each side of the mouth for both groups at 2 months, and 4 months after canine retraction. Results: the velocity of canine was significantly higher on the experimental group than the control group by two times during the first two months after canine retraction. This rate declined to 1.25 times higher after four months. Conclusion: alveolar corticotomy increased orthodontic tooth movement when retracting upper canines.
\end{abstract}

\section{KEYWORDS}

Tooth movement velocity, alveolar corticotomy, canine retraction

\section{INTRODUCTION}

One of the main constraints related to adult orthodontic treatment is without a doubt the significant treatment duration. Canine retraction, which remains a relatively slow process, could considerably lengthen this treatment period, particularly in adults in whom the tissue response to orthodontic application is much slower than that in children and adolescents. According to Buschang ${ }^{4}$, the average duration of orthodontic treatment with extractions varies between 24 and 35 months. This relatively long duration can be an obstacle to the motivation of adult patients, who are more and more likely to desire rapid treatment. In addition, the incidence of carious problems, periodontal damage ${ }^{6,17}$, and root resorptions ${ }^{19}$ increases with treatment duration. Many procedures have been implemented with this in mind, such as administration of local or systemic drugs, physical or mechanical

Address for correspondence:

Amina Mezari - Cité Sonelgaz - Route Nationale - Villa $n^{\circ}$

32 - Ben Aknoun - Alger - Algérie

E-mail: a_mezari@yahoo.fr

Article received: 02-03-2018. Accepted for publication: 03-04-2018.

This is an Open Access article distributed under the terms of the Creative Commons Attribution License (http://creativecommons.org/licenses/by/4.0), which permits unrestricted use, distribution, and reproduction in any medium, provided the original work is properly cited. 
stresses, and surgical means. Alveolar corticotomy associated with orthodontic treatment has been used in many studies to accelerate tooth movement to significantly reduce orthodontic treatment duration. This is a surgical procedure that injures the cortical bone and consists of making lines or perforations only on the outer cortex around the teeth to be moved ${ }^{15}$. The principle of alveolar corticotomy is based on a biological conceptregional acceleratory phenomenon (RAP) - described for the first time by Frost ${ }^{10}$ following a bone fracture. It is a physiological healing phenomenon

\section{MATERIALS AND METHODS}

We conducted a prospective study comparing the rate of upper canine retraction between orthodontic treatment with alveolar corticotomy and conventional orthodontic treatment performed at the DFO of the University Hospital Center of Mustapha, Algiers with the authorization of the ethics committee of the same hospital. The study population consisted of adult patients consulting the orthodontic department as well as students enrolled at the Faculty of Medicine of Algiers. Our sample consisted of 30 adult subjects (23 females and 7 males) with a mean age of 21 years (standard deviation 2 years). Patients were selected according to the following inclusion criteria: 1) class II division 1 malocclusion requiring extraction of the first two maxillary premolars for retraction of the upper canines; 2) complete permanent dentition with healthy upper canines, which had developed on the arch; 3) a good general state of health characterized by an increase in cell turnover with an influx of osteoblasts and osteoclasts on the operative site and a decrease in bone density due to increased osteoclastic activity. This post-operative osteopenia is transient and reversible, and physiological bone healing will allow the gradual restoration of bone density. The main objective of our study is to evaluate the rate of upper canine retraction after alveolar corticotomy compared with that after conventional orthodontic treatment to verify the effectiveness of this technique and its impact on canine retraction.

with absence of any disease contraindicated for surgery; 4) good oral hygiene with no periodontal disease; and 5) no history of orthodontic treatment. Exclusion criteria for patients were 1) impacted or ectopic upper canines, restored upper canines or with abnormal morphology or structure, and canines with endodontic treatment; 2) pregnant patients; 3) smokers; and 4) patients with psychiatric disorders and impaired judgment. We divided our subjects into two groups on a voluntary basis. The control group included 15 patients who received conventional orthodontic treatment. The experimental group also included 15 patients who received orthodontic treatment with alveolar corticotomy in the upper canine region. Explanations regarding the study protocol were given to the patients and additional examinations were performed. Patients were included in the study only after giving written informed consent. 


\section{PRACTICAL ORGANIZATION}

All patients were treated with a standard Edgewise multi-attachment fixture (0.022 inch $\times 0.028$ inch) with a conventional upper arch anchorage. After the first alignment phase, the first upper premolars were extracted and an alveolar corticotomy was performed on the upper canines in the experimental group. Corticotomy was limited to the vestibular cortex of the upper canine

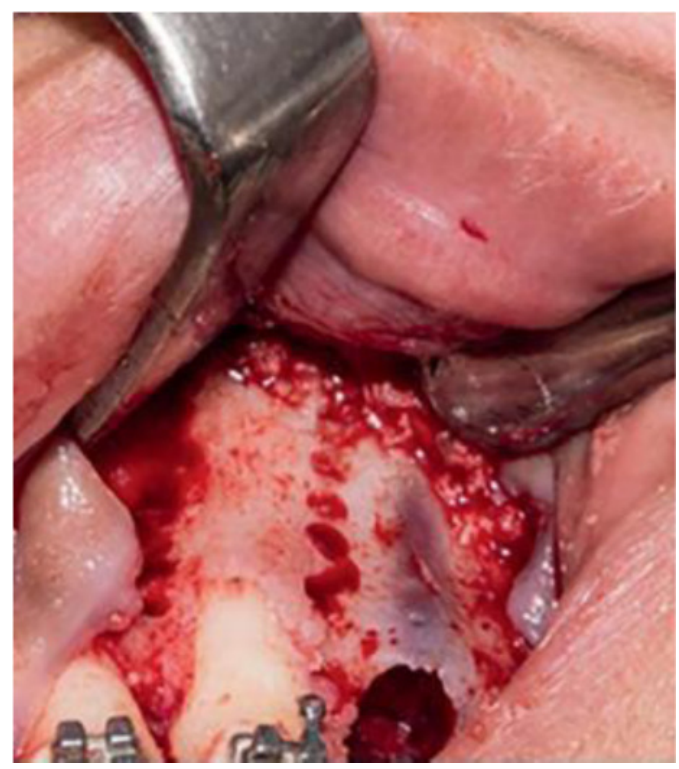

Figure 1 after detachment of a classical mucoperiosteal flap. "Dotted" perforations were made with a medium round bur mounted on a handpiece, at low speed, and under irrigation by circumscribing the canine root without touching it, mesially, distally, and $2 \mathrm{~mm}$ above the apex. The perforations passed through the entire cortical bone without penetrating the medullary bone and remaining $2 \mathrm{~mm}$ below the top of the alveolar ridge (Fig. 1).

The flap was repositioned and sutured with a 4/0 nonabsorbable suture left in place for approximately 10 days. Post-operative medication with antibiotics, corticosteroids, and analgesics had been prescribed to improve the patient's post-operative comfort. Retraction of the upper canines was performed with elastomeric chains on a steel arch 10.016 inch $\times 0.022$ inch). The intensity of the initial retraction force was $100 \mathrm{~g}$, which then increased and was maintained at $150 \mathrm{~g}$. The chains were replaced conventionally in the control group and every 2 weeks during the first 4 months after corticotomy was performed in the experimental group (Fig. 2).
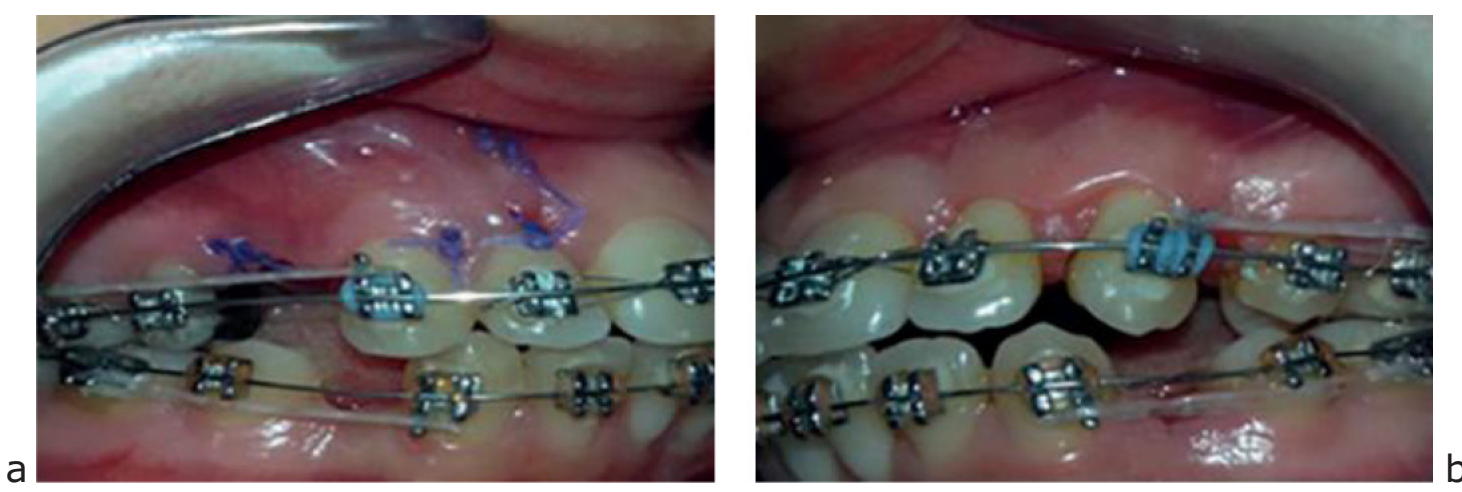

Figure 2 


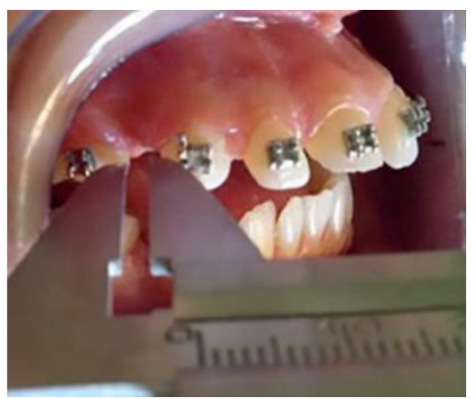

Figure 3
Using a vernier caliper, the canine retraction rates were calculated by measuring the distance between the upper canine and the second upper premolar on each side of the arch at (TO) before the canine retraction phase, then at (T1) and (T2) corresponding, respectively, to 2 and 4 months after upper canine retraction (Fig. 3).

\section{STATISTICAL ANALYSIS}

When comparing the different parameters between the two groups, all tests were performed at a $95 \%$ confidence level. A P-value of $<0.05$ was considered significant for each comparison. The results obtained were analyzed using the XLSTAT software program. The tests used were Shapiro-Wilk and Wilcoxon's test, reduced gap test with Student's law, and Mann-Whitney $U$ test.

\section{RESULTS}

Data analysis was performed for the 30 patients included in the study according to the inclusion criteria. We started the study with 60 upper canines to retract. One canine was excluded in the experimental group for reasons of protocol deviation. In total, the analysis was done on 59 canines that were retracted using two different methods: alveolar corticotomyassisted retraction (experimental group) and conventional non-surgical retraction (control group). The two groups were similar and comparable at the beginning of the study. We found no significant difference in age and sex between the two groups. The rate of canine retraction in the experimental group was faster than that in the control group with a highly significant difference $(P<0.0001)$ (Tables 1 and 2). Comparisons at different periods of canine retraction demonstrated that the average canine retraction rate in the experimental group was approximately twice as high as that in the control group during the first

Table 1: Comparison of the differences between the mean canine retraction rates between the control and experimental groups.

\begin{tabular}{|c|c|c|c|c|}
\hline Periods & $\begin{array}{c}\text { Control group } \\
\text { (mm/month) }\end{array}$ & $\begin{array}{c}\text { Experimental } \\
\text { group } \\
\text { (mm/month) }\end{array}$ & Variation & P-value \\
\hline T0-T1 & $0.81 \pm 0.32$ & $1.59 \pm 0.55$ & 0.78 & $<0.0001$ \\
\hline T1-T2 & $1.04 \pm 0.57$ & $1.30 \pm 0.40$ & 0.26 & 0.017 \\
\hline
\end{tabular}

Abbreviations: TO (baseline): before canine retraction. T1 and T2 correspond respectively to 2 and 4 months after canine retraction. 
Table 2: Study of variations in average rate of upper canine retraction by side in the experimental group.

\begin{tabular}{|c|c|c|}
\hline Periods & $\begin{array}{c}\text { Right canine } \\
\text { (mm/month) }\end{array}$ & $\begin{array}{c}\text { Left canine } \\
\text { (mm/month) }\end{array}$ \\
\hline T0-T1 & $1.57 \pm 0.6$ & $1.61 \pm 0.49$ \\
\hline T1-T2 & $1.39 \pm 0.37$ & $1.22 \pm 0.42$ \\
\hline
\end{tabular}

Abbreviations: TO (baseline): before canine retraction. T1 and T2 correspond respectively to 2 and 4 months after canine retraction.

2 months. This decreased to 1.25 times between 2 and 4 months, without a significant difference between
Table 3: Study of variations in average velocity of upper canine retraction by sex in the experimental group.

\begin{tabular}{|c|c|c|}
\hline Upper canine & $\begin{array}{c}\text { Female } \\
\text { (mm/month) }\end{array}$ & $\begin{array}{c}\text { Male } \\
\text { (mm/month) }\end{array}$ \\
\hline Right & $1.59 \pm 0.27$ & $1.68 \pm 0.26$ \\
\hline Left & $1.65 \pm 0.35$ & $1.84 \pm 0.20$ \\
\hline
\end{tabular}

the right and left sides. Statistical analysis also revealed that there was no significant difference in the canine retraction rate $(P>0.05)$ between males and females (Table 3).

\section{DISCUSSION}

The average rate of upper canine retraction was significantly higher in the experimental group. It appears that alveolar corticotomy significantly accelerates tooth retraction rate in our sample. The results of our study on tooth retraction acceleration are consistent with those of Lino et al. ${ }^{14}$ and Ren et al. ${ }^{16}$ in animal experiments. They are also in line with the works of Suya ${ }^{18}$, Hajji ${ }^{12}$, Chung et al. ${ }^{5}$ and Wilcko et al. ${ }^{20,21}$, in which alveolar corticotomy-assisted orthodontic treatments had been proposed to reduce the duration of orthodontic treatment in adult patients compared with conventional treatments. Our results also corroborate those of Aboul-Ela et al. ${ }^{1}$ and Al-Naoum et al. ${ }^{2}$, which confirmed the acceleration of canine retraction rate after alveolar corticotomy. The explanation for this is "RAP," which reduces bone density and therefore the resistance of the alveolar bone, mainly of the cortical bone, to the orthodontic movement of the tooth . All these variations in rate are due to the transient nature of "RAP," which is triggered by this corticotomy-induced bone lesion, making the healing process 2-10 times faster than in the absence of corticotomy. Yaffe et al. ${ }^{22}$ reported that "RAP" would begin a few days after corticotomy, reach a peak at 1-2 months, and then decrease after that. In our protocol, decortications were performed only on the vestibular cortex without the need for palatal surgery or osteotomy-mobilizing bone grafting blocks around the canines. The advantage of this conservative corticotomy "design" is to reduce the surgical procedure duration as well as the patient's discomfort with postoperative consequences. This would argue, once again, in favor of RAP, which is the basis of the biological explanatory theory of accelerated tooth retraction to the detriment of bone block theory. It would be logical to think like Al-Naoum et al. $^{2}$ and Echchadi ${ }^{7}$ that "RAP" induced by vestibular corticotomy would also have spread to the non-corticotomized palatal cortex of 
the concerned tooth. Indeed, it is well recognized that different corticotomy techniques exist and that the palatal character of the corticotomies tends to disappear. However, it is suggested that these should be minimized around a single protocol and should instead be individualized, responding to the specific needs of the patient being treated and according to elaborate surgical and biomechanical approach$\mathrm{es}^{3}$. During the surgical procedure, we chose to make the conventional flap of the corticotomy technique with an intrasulcular incision around the teeth of the gingival mucosa. Hoogeveen et al. ${ }^{13}$ did not report any particular complication in relation to the different "flap designs" or the different types of decortication "corticotomy designs" used in different studies. Gantes ${ }^{11}$ and
Suya ${ }^{18}$ also claimed that corticotomies in which decortications begin at a distance from the alveolar ridge with an intrasulcular incision have a very low risk of marginal periodontal injury. In our study, we performed corticotomies with a rotary-type handpiece instrument at slow speed and under irrigation. This instrumentation initiated by Wilcko et al. ${ }^{20,21}$ has been used by many authors such as Fischer ${ }^{22}$ Aboul-Ela et al. ${ }^{1}$ and Al-Naoum et al. ${ }^{2}$ during their work on canine retraction after alveolar corticotomy. A systematic review by Hoogeveen et al. ${ }^{13}$ stated that the operative follow-up of patients after corticotomy performed with rotary instruments compared with piezoelectric instruments was identical for both techniques and did not persist more than a week after surgery.

\section{CONCLUSION}

At the end of our study and in view of our results, which coincide with those of many studies, we can no longer ignore the effect of alveolar corticotomy on tooth retraction rate. Observations from clinical trials and animal experiments have clearly demonstrated a temporary acceleration of tooth retraction rate. The selective corticotomy approach combined with the orthodontic treatment that we have adopted, by limiting the surgery to the upper canines, has made it possible to bring together all the literature to widen the field of indications for this technique. However, a well-conducted treatment plan, with early and close activations of equipment for a period of time, is required. Our results showed that it was possible to accelerate upper canine retraction rate using alveolar corticotomy, without any significant difference between the two sexes. This could indeed reduce treatment duration. However, we believe that additional prospective studies with longer observation periods are desirable to justify the biological background of corticotomy techniques and to demonstrate to what extent this surgery could shorten the total orthodontic treatment duration.

Conflict of interest

The authors declare that they have no conflict of interest. 


\section{BIBLIOGRAPHY}

1. Aboul-Ela SM, El-Beialy AR, El-Sayed KM, Selim EM, El-Mangoury NH, Mostafa YA. Miniscrew implant-supported maxillary canine retraction with and without corticotomyfacilitated orthodontics. Am J Orthod Dentofacial Orthop Février 2011:252-9.

2. Al-Naoum F, Hajeer MY, Al-Jundi A. Does alveolar corticotomy accelerate orthodontic tooth movement when retracting upper canines? A split-mouth design randomized controlled trial. J Oral Maxillofac Surg Octobre 2014:1880-9.

3. Béziat JL, Aknin JJ, Babic B. Chirurgie orthognathique piézoélectrique Sciences $E$, editor; 2013.

4. Buschang PH, Campbell M, Ruso S. Accelerating Tooth Movement With Corticotomies: Is It Possible and Desirable? Semin Orthod Décembre 2012:286-294.

5. Chung K, Oh M, Ko S. Corticotomy-assisted orthodontics. J Clin Orthod Mai 2001: 331-339.

6. Doassans MP. Évaluation et traitement des troubles parodontaux liés au déplacement orthodontique de la canine. Rev Orthop Dento Faciale Décembre 1995: 459-471.

7. Echchadi MEM. Apport des corticotomies alvéolaires dans la gestion de l'ancrage en orthodontie. Int Orthod Juin 2014:171-187.

8. Fischer TJ. Orthodontic treatment acceleration with corticotomy-assisted exposure of palatally impacted canines. Angle Orthod Mai 2007:417-420.

9. Frost HM. The regional acceleratory phenomenon. Orthop Clin North Am 1981:725-6.

10. Frost HM. The biology of fracture healing. An overview for clinicians. Part I. Clin Orthop Relat Res Novembre 1989:283-93.

11. Gantes B, Rathbun E, Anholm M. Effects on the periodontium following corticotomyfacilitated orthodontics. Case reports. J Periodontol Avril 1990:234-8.

12. Hajji SS. The influence of accelerated osteogenic response on mandibular decrowding [thesis]. St Louis, St Louis University, 2000.

13. Hoogeveen E, Jansma J, Ren Y. Surgically facilitated orthodontic treatment: a systematic review. Am J Orthod Dentofacial Orthop Avril 2014:51-64.

14. Lino S, Sokada S, Ito G. Acceleration of orthodontic tooth movement by alveolar corticotomy in the dog. Am J Orthod Dentofacial Orthop 2007:131-448.

15. Murphy KG, Wilcko MT, Wilcko WM, Ferguson DJ. Periodontal accelerated osteogenic orthodontics: a description of the surgical technique. J Oral Maxillofac Surg Octobre 2009:216-6.

16. Ren A, LvT, Kang N, Zhao B, Chen Y, Bai D. Rapid orthodontic tooth movement aided by alveolar surgery in beagles. Am J Orthod Dentofacial Orthop Février 2007:1-10.

17. Sorel O, Glez D. Environnement parodontal des canines. Rev Orthop Dento Faciale Juin 2010:199-214.

18. Suya H. Corticotomy in orthodontics. Am J Orthod Dentofacial Orthop 1991;14:207.

19. Weltman B, Vig KW, Fields HW, Shanker S, Kaizar EE. Root resorption associated with orthodontic tooth movement: a systematic review. Am J Orthod Dentofacial Orthop Avril 2010:462-76.

20. Wilcko MH, Wilcko MT, BouquotJE, Ferguson DJ: Rapid orthodontics with alveolar reshaping: Two case reports of decrowding. Int J PeriodonticsRestorative Dent 2001;21:9. 
21. Wilcko WM, Ferguson DJ, Bouquot JE, Wilcko MT. Rapid orthodontic decrowding with alveolar augmentation: Case report. World J Orthod 2003;4:197.

22. Yaffe A, Fine N, Binderman I. Regional accelerated phenomenon in the mandible following mucoperiosteal flap surgery. J Periodontol Janvier 1994:79-83. 